\title{
BIOSSENSOR PARA DETECÇÃO DE STAPHYLOCOCCUS AUREUS BASEADO EM PEPTÍDEO ANTIMICROBIANO MASTOPARANO-L/MO E NANOESTRUTURAS NÚCLEO- CASCA DE $\mathrm{Fe}_{3} \mathrm{O}_{4} @ A u$
}

\author{
A. G. SILVA JUNIOR ${ }^{1,2}$, I. A. M. FRIAS ${ }^{2}$, S. R. SÁ ${ }^{2}$, R. G. LIMA-NETO ${ }^{3}$, \\ O. L. FRANCO ${ }^{4}$, M.D.L. OLIVEIRA ${ }^{1,2}$, e C.A.S. ANDRADE ${ }^{1,2}$ \\ ${ }^{1}$ Programa de Pós-Graduação em Inovação Terapêutica, UFPE, Recife/PE, Brasil. \\ ${ }^{2}$ Departamento de Bioquímica, UFPE, Recife/PE, Brasil. \\ ${ }^{3}$ Departamento de Medicina Tropical, UFPE, Recife, PE, Brasil, \\ ${ }^{4}$ Centro de Análises Proteômicas e Bioquímicas de Brasília, UCB, Brasília/DF, Brasil. \\ E-mail para contato: albertogaldino16@gmail.com
}

\begin{abstract}
RESUMO - Diante de diversas técnicas de deteç̧ão presuntiva de microrganismos, o desenvolvimento de biossensores eletroquímicos têm se destacado devido às suas características como sensibilidade, especificidade e reprodutibilidade, além do curto tempo de resposta. Neste trabalho foram utilizados o Mastoparano-L (Mast), um peptídeo antimicrobiano isolado do veneno de vespas e sua versão modificada (Mast-MO), que atuam nas membranas de microrganismos devido a estrutura cationica anfipática como estratégia para detecção de Staphylococcus aureus. Mast e Mast-MO foram imobilizados em uma monocamada automontada de ácido 4-mercaptobenzóico (MBA) e nanopartículasdo tiponúcleo-cascade $\mathrm{Fe}_{3} \mathrm{O}_{4} @$ @A modificadas por cisteína.A técnica de espectroscopia de impedância eletroquímica foi utilizada para a avaliação do processo de adsorção do MBA, Fe ${ }_{3} \mathrm{O}_{4} @ A$ Au, Mast/Mast-MO e o processo de biointeração frente à bactéria. As plataformas biossensoras obtidas proporcionaram a detecção eletroquímica da bactéria Gram positiva S. aureus, o qual ambos biossensores alcançaram o limite de detecção de 1 UFC.mL $L^{-1}$. A plataforma composta pelo peptídeo Mast-MO demonstrou sensibilidade superior de $10^{4}$ UFC. $m L^{-1}$ devido a inserção da sequência FLPII à sua estrutura. O biossensor desenvolvido com Mast-MO pode ser considerado uma estratégia inovadora a ser aplicada na detecção rápida e sensível de microrganismos presentes na clínica humana e animal.
\end{abstract}

Palavras-chave: Biossensor, impedância, mastoparano, bactéria.

ABSTRACT: With several presumptive detections of microorganisms techniques, the development of electrochemical biosensors has been highlighted due to its characteristics such as sensitivity, specificity, and reproducibility, in addition to the short response time. In this study, we used Mastoparan-L (Mast), an antimicrobial peptide isolated from wasp venom and its modified version (Mast- 
$M O)$ that acts in the membranes of microorganisms due to the amphipathic cationic structure as a strategy to detect Staphylococcus aureus. Mast and Mast$M O$ were immobilizated in self-assembled monolayer of 4-mercaptobenzoic acid $(\mathrm{MBA})$ and cysteine modified $\mathrm{Fe}_{3} \mathrm{O}_{4} @ \mathrm{Au}$ core-shell nanoparticles. Electrochemical impedance spectroscopy was used to evaluate the adsorption process of $\mathrm{MBA}, \mathrm{Fe}_{3} \mathrm{O}_{4} @$ @Au, Mast/Mast-MO and bacteria biointeraction process. The obtained biosensor platforms provided electrochemical detection of Grampositive bacterium S. aureus, with a detection limit of 1 CFU. $m L^{-1}$ for both biosensors. Mast-MO composed platform showed a higher sensitivity to detect up to 104 CFU.mL $L^{-1}$ due to its FLPII additional sequence. Biosensor with Mast-MO is an innovative strategy to be applied in a rapid and sensitive detection of microorganisms present in human and animal clinic.

Keywords: Biosensor, impedance, mastoparan, bacteria.

\section{INTRODUÇÃO}

O Brasil apresenta a agricultura e a pecuária como principais setores da economia, desempenhando um forte papel para o crescimento econômico. $\mathrm{O}$ agronegócio nacional retrata o setor pecuário como um dos mais promissores do país, se qualificando como um dos maiores produtores de carnes bovina, suína e de aves no mundo (FARINA et al., 2003). As regiões Centro-Oeste e Nordeste concentram uma das maiores áreas de produção de carnes no país, o qual apesar do cuidado do produtor, doenças como diarreia aviária e mastite bovina, causada pela bactéria Gram positiva Staphylococcus aureus acometem esses animais da criação agropecuária nacional. Tais fatos podem culminar na redução da qualidade das carnes e por fim, diminuição das vendas, implicando na redução da economia na área (CARDOSO, 2013).

Os microrganismos causadores de infecções em animais também podem alcançar seres humanos principalmente em casos de infecção hospitalar, o qual é definida como a infecção adquirida após a admissão do paciente na unidade hospitalar e que se manifesta durante a internação ou após a alta, quando puder ser relacionada com a internação ou procedimentos hospitalares (GARNER et al., 1988). Bactérias Gram positivas, como as do gênero Staphylococcus e Streptococcus tem ganho elevada atenção devido aos diferentes tipos de infecções que ocasionam, dentre eles o impetigo, fascite necrosante, febre reumática, endocardite, síndrome do choque tóxico, entre outros exemplos (SESHADRI E SETHURAMAN, 2016).

Existem diversos meios de detecção presuntiva para bactérias, nos quais o crescimento em meios de cultura líquidos e sólidos, o uso da técnica ELISA e técnicas moleculares tem destaque. No entanto, tais meios podem apresentar diversos vieses devido ao tempo de crescimento do microrganismo no meio de cultura entre 24-72 horas, problemas de reações cruzadas nos métodos enzimáticos e o alto custo dos equipamentos e de reagentes dos testes moleculares (TERATO et al., 2014; LÓPEZ et al., 2009).

A partir de organismos vegetais e animais podem ser obtidos os peptídeos antimicrobianos (PAMs), que são componentes de seus sistemas imunes inatos. A seletividade dos PAMs e seu modo de ação singular, tornou-os candidatos promissores para o desenvolvimento de novos agentes antibióticos que podem ser usados para superar o problema da resistência a antimicrobianos. Tais peptídeos tem a capacidade de assumir uma conformação anfipática de ligação a membranas celulares, como as de microrganismos (CARNEIRO et al., 2015). O mastoparano-L (INLKALAALAKKIL-NH ${ }_{2}$ ) é um PAM que foi inicialmente isolado do veneno da vespa Vespula lewisii (HIRAI et al., 1979). Recentemente 
sua versão modificada, o Mastoparan-MO (FLPIIINLKALAALAKKIL-NH ${ }_{2}$ ) foi sintetizada, também apresentando excelente interação contra microrganismos patogênicos (SILVA et al., 2015). PAMs podem ser aplicados como agentes de biorreconhecimento frente a microrganismos através do desenvolvimento de dispositivos sensores impedimétricos (SPIZZIRRI e CIRILLO, 2016)

Biossensores eletroquímicos constituem-se uma alternativa sensível e rápida para detecção desses microrganismos. São constituídos de um elemento sensor biológico ativo, que pode variar de: anticorpos, enzimas, fragmentos de DNA, proteínas e células, o qual será responsável pela especificidade ao analito, o qual nesse presente trabalho foi utilizado o peptídeo antimicrobiano Mastoparano-L (Mast) e sua versão modificada (Mast-MO). Também possuem um transdutor físico-químico, que converterá a detecção bioquímica para um sinal elétrico detectável para ser lido em um princípio de detecção impedimétrico, por exemplo (TURNER, 2013).

Portanto, o presente trabalho teve como objetivo a avaliação da plataforma nanoestruturada formada por $\mathrm{MBA}_{-} \mathrm{Fe}_{3} \mathrm{O}_{4} @ \mathrm{Au}_{-}$Mastoparano, frente às diferentes concentrações de Staphylococcus aureus, por meio da espectroscopia de impedância eletroquímica (EIE).

\section{MATERIAIS E MÉTODOS}

Materiais - $\mathrm{O}$ ferri $\left(\mathrm{K}_{3}\left[\mathrm{Fe}(\mathrm{CN})_{6}\right]\right)$ e ferrocianeto de potássio $\left(\mathrm{K}_{4}\left[\mathrm{Fe}(\mathrm{CN})_{6}\right]\right)$, óxido férrico e óxido ferroso foram obtidos da VETEC (Brasil). A cisteína (Cys), o N-etil-3-[3dimetilaminopropil]carbodiimida (EDC), N-hidroxisuccinimida (NHS), ácido 4mercaptobenzóico (MBA) foram adquiridos da Sigma Aldrich (St Louis, USA). Os peptídeos antimicrobianos Mastoparano-L e Mastoparano-MO foram prospectados, purificados e posteriormente sintetizados. O processo de síntese foi baseado na técnica de fase sólida N-9fluorenylmethyloxycarbonyl (Fmoc) e purificado por meio da cromatografia líquida de alta eficiência (HPLC). Todos os reagentes químicos e solventes foram de grau analítico e utilizados como recebidos, sem purificação adicional. A água ultra-pura utilizada foi obtida a partir de sistema de purificação Milli-Q (Billerica, EUA).

Síntese e modificação das nanopartículas magnéticas - As núcleo-casca de $\mathrm{Fe}_{3} \mathrm{O}_{4} @ \mathrm{Au}$ foram sintetizadas segundo Tamer et al., 2010, com algumas alterações. A modificação das nanopartículas seguiu-se adicionando $25 \mathrm{~mL}$ de água a um erlenmeyer de $50 \mathrm{~mL} ; 5,7 \mathrm{mM}$ de cisteína e $15 \mathrm{mg}$ das nanopartículas previamente sintetizadas. Em seguida, colocou-se o erlenmeyer em ultrassom durante 10 minutos e agitação orbital por 24 horas em $150 \mathrm{rpm}$. Por fim, as nanopartículas modificadas foram lavadas em água deionizada repetidas vezes, e separadas por atração magnética.

Montagem da plataforma biossensora: Inicialmente, o eletrodo de trabalho com superfície de ouro foi limpo utilizando $\mathrm{HClO}$. A modificação de superfície do eletrodo se deu inicialmente por meio da aplicação de $4 \mu \mathrm{L}$ de MBA $(1 \mathrm{mM})$, durante o tempo de 2 minutos. Em seguida, houve a aplicação de $4 \mu \mathrm{L}$ da $\mathrm{Fe}_{3} \mathrm{O}_{4} @ \mathrm{Au}$ modificada por 2 minutos, finalizandose com a aplicação dos peptídeos Mast ou Mast-MO $(4 \mu \mathrm{L}, 100 \mu \mathrm{M})$ e BSA por 2 minutos cada. Os agentes EDC:NHS (0.4M e $0.1 \mathrm{M}$, respectivamente) foram utilizados para a ativação dos grupamentos carboxila e amina livres. Diferentes concentrações da bactéria $S$. aureus foram preparadas de acordo com a escala de McFarland (1 a $10^{6} \mathrm{UFC}_{\mathrm{mL}}{ }^{-1}$ ) e aplicadas à superfície do biossensor por 2 minutos, sendo em seguida avaliada a detecção por técnicas eletroquímicas.

Medidas eletroquímicas - As análises de EIE foram realizadas por meio de um 
potenciostato/galvanostato AUTOLAB (Metrohm, Holanda) em uma célula eletroquímica contendo três eletrodos imersos em $10 \mathrm{~mL}$ de $10 \mathrm{mM}$ ferro-ferricianeto de potássio, $\mathrm{K}_{4}\left[\mathrm{Fe}(\mathrm{CN})_{6}\right]^{4-} / \mathrm{K}_{3}\left[\mathrm{Fe}(\mathrm{CN})_{6}\right]^{3-}$ [1:1] em tampão fosfato (PBS, pH 7.4), a qual atua como sonda redox. Eletrodos de platina e de disco de ouro $(\phi=2 \mathrm{~mm})$ foram usados como contra-eletrodo e eletrodo de trabalho, respectivamente, tendo como eletrodo de referência $\mathrm{Ag} / \mathrm{AgCl}$ (saturado em $\mathrm{KCl} 3 \mathrm{M}$ ). A voltametria cíclica (VC) foi realizada com um potencial de varredura entre 0,8 e $-0,3 \mathrm{~V}$ a uma taxa de varredura de $50 \mathrm{mV} / \mathrm{s}^{-1}$. Os espectros de impedância (EIE) foram registrados numa faixa de frequência de $100 \mathrm{mHz}$ a $100 \mathrm{kHz}$ em amplitude do potencial de onda senoidal aplicado de $10 \mathrm{mV}$.

\section{RESULTADOS E DISCUSSÃO}

A EIE teve como objetivo fornecer informação sobre o processo de modificação de superfície do eletrodo de trabalho, bem como a detecção das diferentes concentrações de $S$. aureus preparadas em solução salina ( 1 a $\left.10^{4} \mathrm{UFC} \cdot \mathrm{mL}^{-1}\right)$ baseando-se na medida da resistência a transferência de carga $\left(\mathrm{R}_{\mathrm{ct}}\right)$ que ocorre na interface do eletrodo com a solução adjacente.

Figura 1 - Diagrama de Nyquist do processo de montagem do sistema MBA_Fe $3 \mathrm{O}_{4} @$ Au_Mastoparano, sendo o mastoparano em sua versão normal (Mast-L) (a); e em sua versão modificada (Mast-MO) (b).
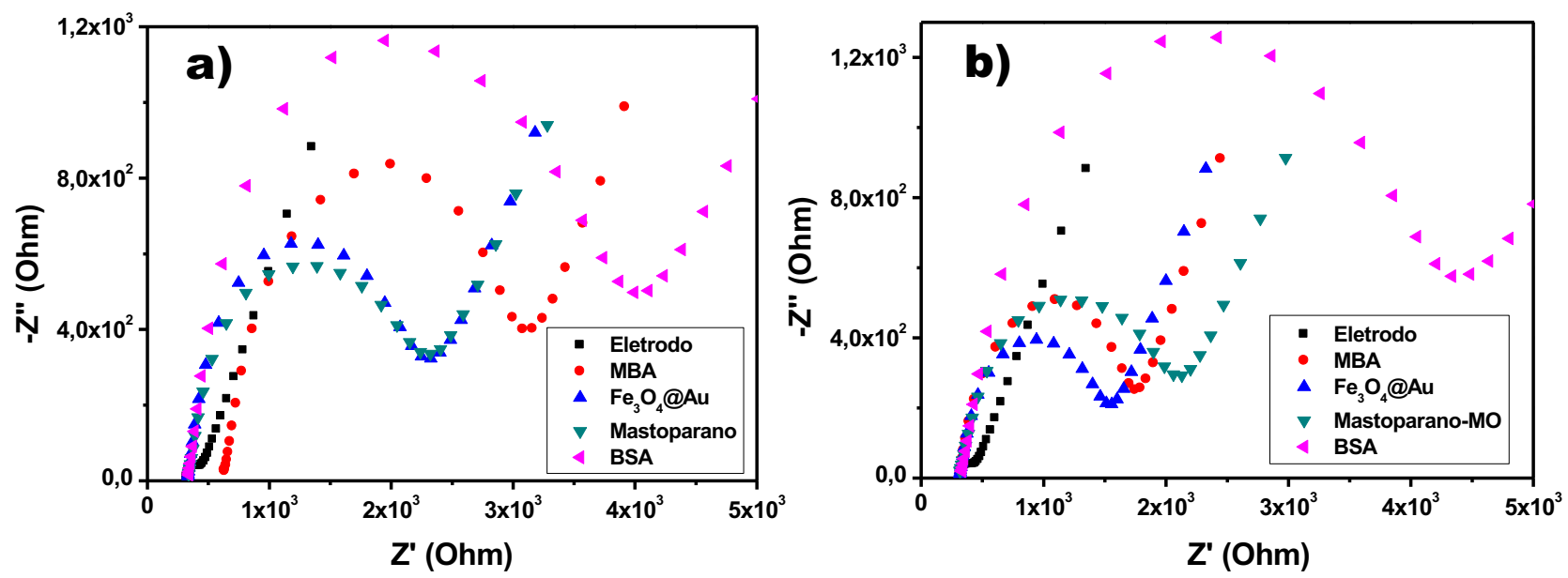

A Fig. 1a representa o processo da montagem da plataforma biossensora utilizando o PAM mastoparano em sua sequência de aminoácidos normal (Mast) e a Fig. 1b a plataforma fazendo uso do mastoparano em sua versão modificada (Mast-MO), o qual houve a inserção da sequência dos aminoácidos FLPII. A caracterização eletroquímica da superfície do eletrodo de ouro limpo demonstrou um aumento da resposta impedimétrica. Ambas plataformas apresentaram uma variação da resistência a transferência de carga, à medida que cada componente do biossensor era inserido. Inicialmente, MBA pontuou um aumento na $\mathrm{R}_{\mathrm{ct}} \mathrm{em}$ cada plataforma, indicando a adequada formação da monocamada adsorvida na superfície do eletrodo de trabalho, obstruindo a transferência de elétrons na interface com o par redox. Paralelo a essa etapa, seguiu-se a aplicação das nanopartículas núcleo-casca de $\mathrm{Fe}_{3} \mathrm{O}_{4} @ \mathrm{Au}$ modificadas com cisteína, e como esperado, devido a aplicação prévia dos agentes EDC:NHS que favorece a ativação de grupos carboxila e aminas livres, o $\mathrm{R}_{\mathrm{ct}}$ diminuiu. Em seguida, houve a adsorção do PAM, apresentando uma redução do $R_{c t}$ para o Mast (a) e um discreto 
aumento para o Mast-MO (b). Finalizando a montagem do biossensor, aplicou-se BSA para a obstrução de sítios livres na superfície de ouro do eletrodo de trabalho, impedindo a ligação de moléculas inespecíficas.

Após encerrada a montagem da plataforma nanoestruturada, seguiu-se a adição das diferentes concentrações de $S$. aureus à superfície de cada biossensor, cuja bactéria foi preparada em meio ágar Mueller Hinton, com crescimento em estufa por $24 \mathrm{~h}$ a $37^{\circ} \mathrm{C}$. Diferentes concentrações da bactéria foram preparadas em solução salina, de acordo com a escala de McFarland, sendo obtido ao final as concentrações que variam de 1 a $10^{4}$ UFC.mL ${ }^{-}$ ${ }^{1}$, sendo por fim, aplicadas à superfície da plataforma biossensora nanoestruturada.

Figura 2 - Diagrama de Nyquist do biossensor MBA_Fe $\mathrm{O}_{4} @ \mathrm{Au}$ _Mastoparano com o PAM em sua sequência normal (a) e modificada (b) frente às diferentes concentrações de Staphylococcus aureus, que vão de uma faixa entre 1 a $10^{4}$ UFC. $\mathrm{mL}^{-1}$, de acordo com a escala de McFarland.
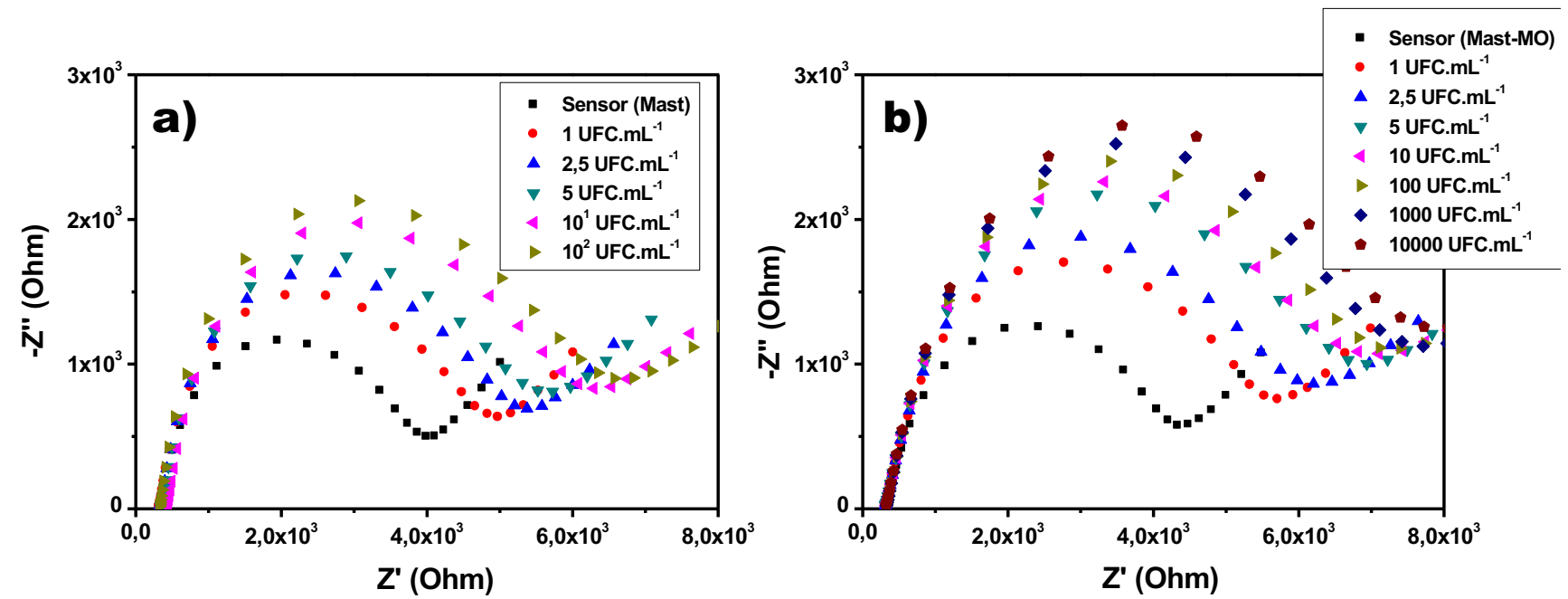

Após interação de cada biossensor com as bactérias, observa-se um aumento sequencial do semicírculo de Cole-Cole. A plataforma biossensora formada pelo peptídeo antimicrobiano Mast (Fig. 2a) apresentou um limite de detecção de 1 UFC.mL ${ }^{-1}$, com pico de detecção em $10^{2}$ UFC.mL ${ }^{-1}$. Em contrapartida, o biossensor composto por Mast-MO, conforme visto na Figura $2 b$, exibiu maior sensibilidade frente as diferentes concentrações da bactéria, com limite de detecção também de 1 UFC.mL, mas podendo detectar até $10^{4}$ UFC.mL ${ }^{-1}$. Quando os microrganismos são reconhecidos pelo biossensor com Mast e MastMO, a ligação com as bactérias ocorrerá, de início, por meio de interações eletrostáticas. Esta observação suporta a hipótese de que a interação inicial dos PAMs que são $\alpha$-hélice com as membranas dos microrganismos alvo ocorre através de atração eletrostática de aminoácidos carregados positivamente dos PAMs com os fosfolipídios carregados negativamente na membrana bacteriana (MATSUZAKI et al., 1997).

Em relação a maior afinidade com as bactérias e suas diferentes concentrações, segundo um estudo recente realizado com PAMs que tiverem a inserção da sequência hidrofóbica "FLPII" a sua estrutura original (como o Mast-MO, cuja sequência é: FLPIIINLKALAALAKKIL-NH ${ }_{2}$ ) apontou uma melhor aplicabilidade. De acordo com sua natureza conhecida por interagir com diferentes tipos de membranas e organelas, acredita-se que a sequência FLPII possa aumentar a afinidade do peptídeo modificado frente as membranas bacterianas, como as do $S$. aureus, explicando a maior sensibilidade apresentada pelo biossensor com Mast-MO (SILVA et al., 2016). 


\section{CONCLUSÃO}

A plataforma biossensora nanoestruturada formada por MBA_Fe $\mathrm{F}_{3} @ \mathrm{Au}$ _Mastoparano mostrou-se estável e sensível frente as diferentes concentrações da bactéria Staphylococcus aureus, alvo do estudo, o qual foram avaliados por meio da EIE. O biossensor com o peptídeo Mast-MO exibiu maior sensibilidade com limite de detecção de 1 a $10^{4}$ UFC.mL ${ }^{-1}$, indicando o presente biossensor como uma proposta de biodispositivo rápido e eficiente para detecção de microrganismos de interesse clínico humano e animal.

\section{REFERÊNCIAS}

CARDOSO, Alexander Machado. BIOPROSPECÇÃO DE NOVOS GENES PARA A INDÚSTRIA USANDO METAGENOMA E BIOINFORMÁTICA. Acta Scientiae et Technicae, v. 1, n. 1, 2013.

CARNEIRO, V. A. et al. Antimicrobial peptides: from synthesis to clinical perspectives. The battle against microbial pathogens: basic science, technological advances and educational programs, 1st edn. Formatex Research Center, Spain, p. 81-90, 2015.

FARINA, Elizabeth MMQ et al. Desempenho do agronegócio no comércio exterior e governança nos sistemas agroindustriais das carnes de suínos e das carnes bovinas. ANPECAssociação Nacional dos Centros de Pós-graduação em Economia. Belo Horizonte, MG, 2003.

GARNER, J. S. et al. CDC definitions for nosocomial infections 1988. Zeitschrift fur arztliche Fortbildung, v. 85, n. 17, p. 818-827, 1991.

HIRAI, Yuko et al. A new mast cell degranulating peptide" mastoparan" in the venom of Vespula lewisii. Chemical and Pharmaceutical Bulletin, v. 27, n. 8, p. 1942-1944, 1979.

LÓPEZ, María M. et al. Are molecular tools solving the challenges posed by detection of plant pathogenic bacteria and viruses?. Current issues in molecular biology, v. 11, n. 1, p. 13, 2009.

MATSUZAKI, Katsumi et al. Interactions of an antimicrobial peptide, magainin 2, with outer and inner membranes of Gram-negative bacteria. Biochimica et Biophysica Acta (BBA)-Biomembranes, v. 1327, n. 1, p. 119-130, 1997.

SESHADRI, Divya; SETHURAMAN, Gomathy. Gram Positive Bacterial Infections. Comprehensive Approach to Infections in Dermatology, p. 15, 2016.

SILVA, O. N. et al. An anti-infective synthetic peptide with dual antimicrobial and immunomodulatory activities. Scientific reports, v. 6, 2016.

SILVA, Osmar Nascimento et al. Modificação incremental de peptídeos: novas perspectivas para o tratamento de infecções e erradicação de biofilmes bacterianos. 2015 . 
SPIZZIRRI, Umile Gianfranco; CIRILLO, Giuseppe (Ed.). Food Safety: Innovative Analytical Tools for Safety Assessment. John Wiley \& Sons, 2016.

TAMER, Uğur et al. Synthesis of magnetic core-shell Fe3O4-Au nanoparticle for biomolecule immobilization and detection. Journal of Nanoparticle Research, v. 12, n. 4, p. 1187-1196, 2010.

TERATO, Kuniaki et al. Preventing intense false positive and negative reactions attributed to the principle of ELISA to re-investigate antibody studies in autoimmune diseases. Journal of immunological methods, v. 407, p. 15-25, 2014.

TURNER, Anthony PF. Biosensors: sense and sensibility. Chemical Society Reviews, V. 42, n. 8, p. 3184-3196, 2013.

\section{AGRADECIMENTOS}

A CAPES, ao Centro de Análises Proteômicas e Bioquímicas de Brasília, ao Departamento de Micologia-UFPE, CNPq e INCT. 